\title{
Randomized, prospective, efficacy and pharmacoeconomic trial of short course combination antiviral of lamivudine and adefovir versus entecavir monotherapy in HBeAg-positive chronic hepatitis B
}

\author{
ZB He ${ }^{1 *}$, QY Chen ${ }^{1}$, JS Zhu ${ }^{2}$, ZM Lin ${ }^{2}$, MG Cai $^{2}, \mathrm{XH} \mathrm{Feng}^{2}$ and KZ Liu ${ }^{3}$ \\ ${ }^{1}$ The Fifth People's Hospital of Shanghai, Fudan University Shanghai 200240, \\ China. \\ ${ }^{2}$ Taizhou Hospital of Zhejiang Province, Wenzhou Medical College China. \\ ${ }^{3}$ The First Affiliated Hospital of college of Medicine, Zhejiang University China.
}

Accepted 25 March, 2013

\begin{abstract}
The aim of this study was to compare the safety, efficacy, and pharmacoeconomics of the diminishing type antiviral combination of lamivudine and adefovir group (LA group) and entecavir monotherapy group (E group) in HBeAg-positive chronic hepatitis B. One hundred (100) patients were randomized equally to LA group, and E group in a multi-center randomized clinical trial. In the LA group, the earliest time for lamivudine discontinuation was 12 weeks and adefovir monotherapy continued until 96 weeks. Group E received entecavir monotherapy for 96 weeks. At 12 weeks, the hepatitis B virus (HBV) DNA suppression and ALT normalization rates in LA group were both comparable to E group. At weeks 24 and 48 of treatment, the difference in virological response (VR) and HBeAg seroconversion between LA group and $E$ group was not significant, while similar results were observed for the biochemical response (BR). At 96 weeks, HBeAg seroconversion of LA group were higher than that of the $E$ group, but the difference was still not statistically significant, while BR and VR in LA and E group were similar. At the same time, no virological breakthrough or drug resistance occurred in either of the two treatment groups by week 96 of the study. Both treatment strategies were well tolerated, with a low incidence of adverse reaction. The costs of all items related to LA group were lower than those related to E group (RMB $¥ 14,480.13$ vs. RMB $¥ 28,818.47 ; t=164.78, p<0.001$ ). This study demonstrates that diminishing type antiviral combination of lamivudine and adefovir is economical, safe, and effective in $\mathrm{HBeAg}$ positive chronic hepatitis $B$.
\end{abstract}

Key words: Chronic hepatitis B, HBeAg-positive, lamivudine, adefovir dipivoxil, combination treatment, entecavir, monotherapy, pharmacoeconomic.

\section{INTRODUCTION}

Antiviral therapy is a treatment for chronic hepatitis B. Domestically and internationally approved pharmacotherapies include interferon $\alpha$, pegylated interferon a, lamivudine, adefovir dipivoxil, entecavir, etc. In the clinical setting, these drugs have both advantages and disadvantages. One of major concerns of lamivudine therapy is increased incidence of drug resistance. Lamivudine is safe and strongly suppresses viral activity, but has high rates of drug resistance. Once the reverse transcriptase 204 mutation is present, cross-resistance to 
telbivudine and entecavir leads to decreased efficacy of those drugs. Adefovir dipivoxil has high rates of seroconversion and low resistance and no cross resistance with other nucleoside analogs, but antiviral activities are weak and onset of therapeutic response is slow. In summary, due to different mutation sites compared to the other three nucleoside analogs, ADV was selected as a basic agent of combination therapy. As the first approved agent for CHB patients, LAM was selected due to the abundant clinical experience and lowest cost. Evidence-based medicine identified that combination therapy could reduce drug-associated resistance to ensure long-term therapy (Degertekin and Lok, 2009), the combination of ADV and LAM results in greater viremia reduction than ADV monotherapy (Wang et al., 2013).

ETV is a deoxyguanosine analog with powerful activity in inhibiting viral replication. It is regarded as a high genetic barrier drug, as more than three sites for drug resistance related mutation are required (European Association for the Study of the Live, 2012). Available data indicate that ETV was recommended as a first line option for long-term treatment of naive $\mathrm{CHB}$ patients instead of LAM resistant patients. In naive CHB patients, the 5-year rate of phenotypic resistance and virus breakthrough-related phenotype resistance were only 1.2 and $0.8 \%$, respectively in patients treated with ETV (Tenney et al., 2009), However, it is very expensive and has been shown to be tumorigenic in laboratory animals while the clinical response is comparable to other antivirals. Thus, LAM and ADV were selected for the de novo combination treatment option. It is currently suggested that initial therapies involving either a combination of nucleoside/nucleotide analogs or monotherapy are both good options to prevent the development of resistance, especially, for the patients who need long-term treatment (Ayoub and Keeffe, 2008); however, relevant data from forecast research on efficacy, potential side effects, or an economic evaluation for the two strategies are rare.

It has been difficult to identify a method to judiciously apply combination therapy. Our design of optimizing the schedule for lamivudine/adefovir combination therapy followed by maintenance adefovir monotherapy for treating $\mathrm{HBeAg}$-positive chronic hepatitis B patients achieved encouraging results and is presented in this report. The purpose of this trial was to compare the safety, efficacy, and pharmacoeconomics of the diminishing type antiviral combination and entecavir monotherapy in $\mathrm{HBeAg}$-positive chronic hepatitis $\mathrm{B}$.

\section{MATERIALS AND METHODS}

\section{Case selection}

This study is a multi-center, randomized, clinical study whose design was examined and approved by the ethics committee. All patients voluntarily entered the study and paid for medical treatment on their own. Patients were followed by telephone or home interview, and the data collection was performed by staff blinded to patients' treatment. A total of 100 of HBeAg-positive chronic hepatitis B patients were enrolled. The diagnosis and efficacy assessment criteria conform to the EASL Clinical Practice Guidelines: Management of chronic hepatitis B virus infection.

\section{Inclusion criteria}

The inclusion criteria includes the following:

1. Patients are between 30 to 60 years-of-age of both gender;

2. HBV serum markers: positive $\mathrm{HBsAg}$ and $\mathrm{HBeAg}$ for at least 6 months and serum HBV DNA $>10^{5}$ copies $/ \mathrm{ml}$;

3. Serum alanine aminotransferase (ALT) must have been analyzed within one month prior to the study;

4. The patient must have never received HBV antiviral therapy;

5. Female patients of childbearing age must be on birth control for the duration of the study

6. Serum anti HBclgM positive.

\section{Exclusion criteria}

The exclusion criteria includes the following:

1. Diagnosis of hepatocellular carcinoma;

2. Clinical symptoms of decompensated liver disease;

3. Creatinine clearance $<70 \mathrm{ml} / \mathrm{min}$;

4. ALT > 10-fold over normal limits at the time of screening or has had transient liver decompensation due to acute illness;

5. Hemoglobin $<10 \mathrm{~g} / \mathrm{dl}$, neutrophils $<1.5 \times 10^{9} / \mathrm{L}$, and platelets $<$ $80 \times 10^{9} / \mathrm{L}$;

6. Other evidence of active liver disease (hepatitis A, E, C, HDV, HIV, and autoimmune disease);

7. Use of nephrotoxic drugs (example vancomycin, adefovir, cisplatin, etc.) within two months prior to the study;

8. The patient has been determined to have difficulties with compliance. The assessment was based on patients' lifestyle, medicine-taking habit, and their knowledge and attitude towards anti-viral therapies;

9. In addition to chronic hepatitis B, the patient has other serious organic or psychiatric disorders.

\section{Study design}

This study was a randomized, controlled, and multi-center clinical trial. Randomization of patient groups was performed with randomization tables, which extended to each clinical center. One hundred (100) patients were randomly assigned at $1: 1$ ratio into the diminishing type antiviral combination of lamivudine and adefovir group (LA group), entecavir monotherapy group (E group). The first 12 to 24 weeks of the LA group was the intensification phase where combined therapy of lamivudine and adefovir were administered. Patients in the LA group were prescribed LAM $100 \mathrm{mg}$ and ADV 10 $\mathrm{mg}$ per day. During the phase of weeks 12-24, if HBV DNA falls below $1.0 \times 10^{3}$ copies $/ \mathrm{ml}$ (undetected level), lamivudine was terminated and adefovir monotherapy is continued. Lamivudine was also terminated at 24 weeks even if HBV DNA did not fall below $1.0 \times 10^{3}$ copies $/ \mathrm{ml}$, which is also followed by adefovir monotherapy , and then into the maintenance treatment phase. Patients in the $\mathrm{E}$ group were prescribed entecavir at $0.5 \mathrm{mg}$ per day. The duration of the clinical trial was 96 weeks.

\section{Observation and follow-up}

Follow-up of the two groups were performed at initiation and during 
Table 1. Baseline characteristics of patients by group.

\begin{tabular}{|c|c|c|c|c|c|c|c|c|c|}
\hline \multirow[t]{2}{*}{ Group } & \multirow[t]{2}{*}{ Cases } & \multicolumn{2}{|c|}{ Sex } & \multicolumn{2}{|c|}{ Age (Years) } & \multicolumn{2}{|c|}{$A L T(\times U L N)$} & \multicolumn{2}{|c|}{$\begin{array}{c}\text { HBV DNA } \\
\left(\log _{10} \text { copies/ml) }\right.\end{array}$} \\
\hline & & $\mathbf{M}$ & $\mathbf{F}$ & Mean \pm SD & Median(range) & Mean $\pm S D$ & Median(range) & Mean \pm SD & Median (range) \\
\hline LA & 45 & 32 & 13 & $39.2 \pm 6.3$ & $38.0(30-54)$ & $5.1 \pm 2.1$ & $5.5(2-8.5)$ & $8.2 \pm 0.8$ & $8.5(6.6-9.8)$ \\
\hline E & 47 & 33 & 14 & $39.0 \pm 6.1$ & $38.0(31-54)$ & $4.6 \pm 2.1$ & $4.0(2-8.5)$ & $8.1 \pm 0.9$ & $8.4(6.5-9.8)$ \\
\hline
\end{tabular}

the weekends following weeks $12,24,36,48,60,72,84,96$ during the trial. Follow-up clinical assessments include: history and physical examination, quantitative HBV DNA(PCR), two pairs of semi for hepatitis $B(H B V-M)$, serum biochemistry, alpha-fetoprotein, etc. LAM-, ADV-, and ETV-associated mutations were assessed for patients with virologic breakthrough via direct sequencing. Normal value of $A L T$ was $0-40 \mathrm{IU} / \mathrm{L}$.

\section{Pharmacoeconomics}

In the present study, the pharmacoeconomic analysis was of the cost-minimization type. Only the costs of the clinical treatment (those directly related to the health care system: medical care, observation and follow-up, medications) were taken into consideration. Indirect costs related to lost productivity, as well as intangible costs (those related to impaired quality of life), were not calculated.

For patients in the two groups, the costs were calculated separately for each of the following aspects: medical visits; antiviral medications; and medications for the treatment of adverse effects.

\section{Statistical analysis}

Quantitative data were presented as the mean \pm standard deviation (SD) (range), categorical data were presented as counts and percentages, and HBV DNA levels were presented as log transformation. Data were analyzed using the SPSS software package version 13.0. The $t$ test was used for quantitative variables, while Pearson Chi-Square was used for categorical variables. All tests of significance were two-tailed, and significance was defined as $P<0.05$.

\section{RESULTS}

\section{Baseline characteristics}

Between November 2007 and February 2011, 100 eligible patients participated in this clinical trial. The LA group contained 50 cases, of which three exhibited poor compliance, one traveled abroad for business, and one enrolled in another treatment program at a nonparticipating center. A total of five cases in the LA group were omitted from analysis and 45 patients completed the trial. The E group contained 50 cases; three patients withdrew due to fear of drug tumorigenicity, resulting in 47 patients completing the trial. The baseline characteristics of the patients were similar and no statistically significant differences were observed (Table 1).

\section{Virological response}

\section{Suppression of serum HBV DNA}

At baseline, serum HBV DNA levels for the two groups were similar. At 12 weeks, the mean serum levels of HBV DNA for the LA and $E$ groups were lower by $4.663 \pm 0.515$ $\log 10$ copies $/ \mathrm{ml}$ and $4.447 \pm 0.611 \log 10$ copies $/ \mathrm{ml}$, respectively. There were no statistical difference in HBV DNA reduction between the LA and $E$ groups $(t=1.825$, $P=0.071$ ). At 24 weeks, the average reduction in $\mathrm{HBV}$ DNA levels between group LA $(5.132 \pm 0.711 \log 10$ copies $/ \mathrm{ml})$ and group $E(4.908 \pm 0.736 \log 10$ copies $/ \mathrm{ml})$ were comparable $(t=1.48, P=0.142)$. At 36 weeks, HBV DNA in the LA group continued to show improvement and decreased by $5.197 \pm 0.766 \log 10 \mathrm{copies} / \mathrm{ml}$, which was still comparable to the $E$ group, whose reduction by $5.078 \pm 0.822 \log 10$ copies $/ \mathrm{ml} \quad(\mathrm{t}=0.718, \mathrm{P}=0.474)$. Both therapy strategies can very effectively inhibit viral replication. The difference was not statistically significant. From 48 weeks, the HBV DNA level of two groups had remained at the undetected level $\left(<10^{3}\right.$ copies $\left./ \mathrm{ml}\right)$. The average reduction in HBV DNA level in the LA group compared to baseline levels was $5.212 \pm 0.785 \log 10$ copies $/ \mathrm{mL}$ at weeks 48, 60, 72, 84, and 96 of treatment, respectively. In the $E$ group, the average reduction in HBV DNA level was $5.117 \pm 0.850 \log 10$ copies $/ \mathrm{mL}$ at weeks $48,60,72,84$, and 96, respectively. No statistically significant difference existed between the two groups $(\mathrm{t}=0.558, \mathrm{P}=0.578)$ (Figure 1).

\section{Rates of undetectable serum HBV DNA}

At 12 weeks, groups LA and E had negative HBV DNA test rates of $47 \%(21 / 45)$ and $36 \%(17 / 47)$, the difference between $L A$ and $E$ was not statistically significant $(x 2=1.04, P>0.05)$. At 24 weeks, the negative HBV DNA test rates for two groups were $89 \%(40 / 45)$ and $74 \%$ $(35 / 47)$, and the differences between two groups were also not statistically significant $(X 2=3.17, P>0.05)$. At 36 weeks, the negative HBV DNA test rates in the LA and $E$ group were $93 \%(42 / 45)$ and $89 \%$ (42/47), respectively. The difference was not statistically significant $(X 2=0.46$, $P>0.05)$. From 48 weeks. the negative HBV DNA test rates for two groups were 100\% (45/45) and 100\% (47/47) 


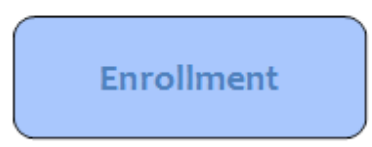

Assessed for eligibility $(n=150)$

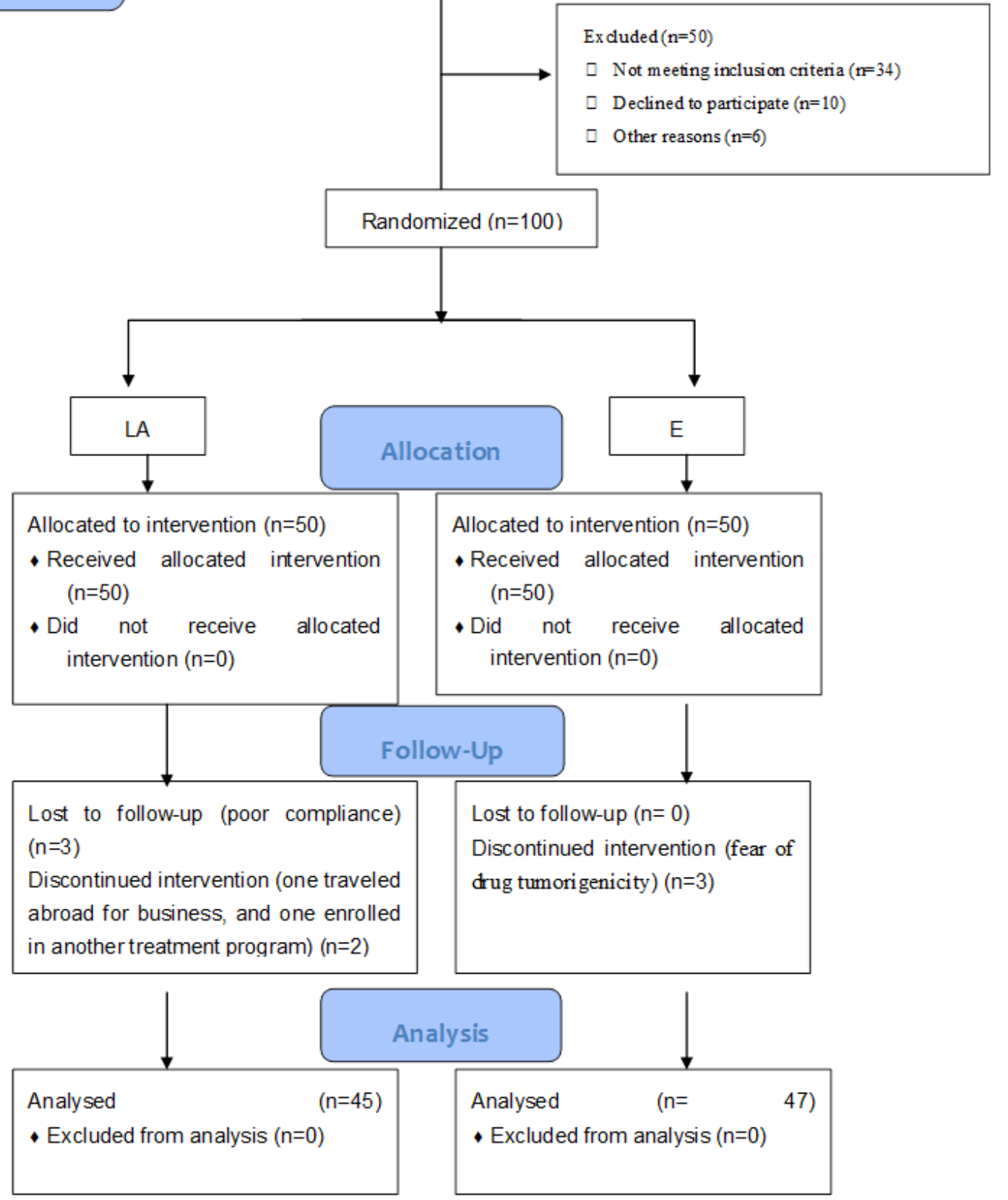

Figure 1. Changes in HBV DNA copy number $\left(\log _{10}\right.$ copies $\left./ \mathrm{ml}\right)$.

by weeks $48,60,72,84$ and 96 , and the difference was not statistically significant $(P>0.05)$ (Figure 2$)$.

\section{Serological response (rates of $\mathrm{HBeAg}$ seroconversion)}

At 24 weeks, there were 8 and 5 patients who had $\mathrm{HBeAg} /$ anti-HBe serological conversion in the LA and $\mathrm{E}$ group, respectively; the $\mathrm{HBeAg}$ seroconversion rates of the LA and $E$ groups were 18 and $11 \%$, respectively. The difference between two groups was not statistically significant $(X 2=0.97, P>0.05)$. At 48 weeks, the $\mathrm{HBeAg}$ seroconversion rates in the LA group continued to show improvement and had achieved 31\% (14/45), which was still comparable to the $\mathrm{E}$ group, whose seroconversion rates was $26 \%(12 / 47)(x 2=0.35, P>0.05)$. However, after 48 weeks, HBeAg seroconversion of LA group continued 


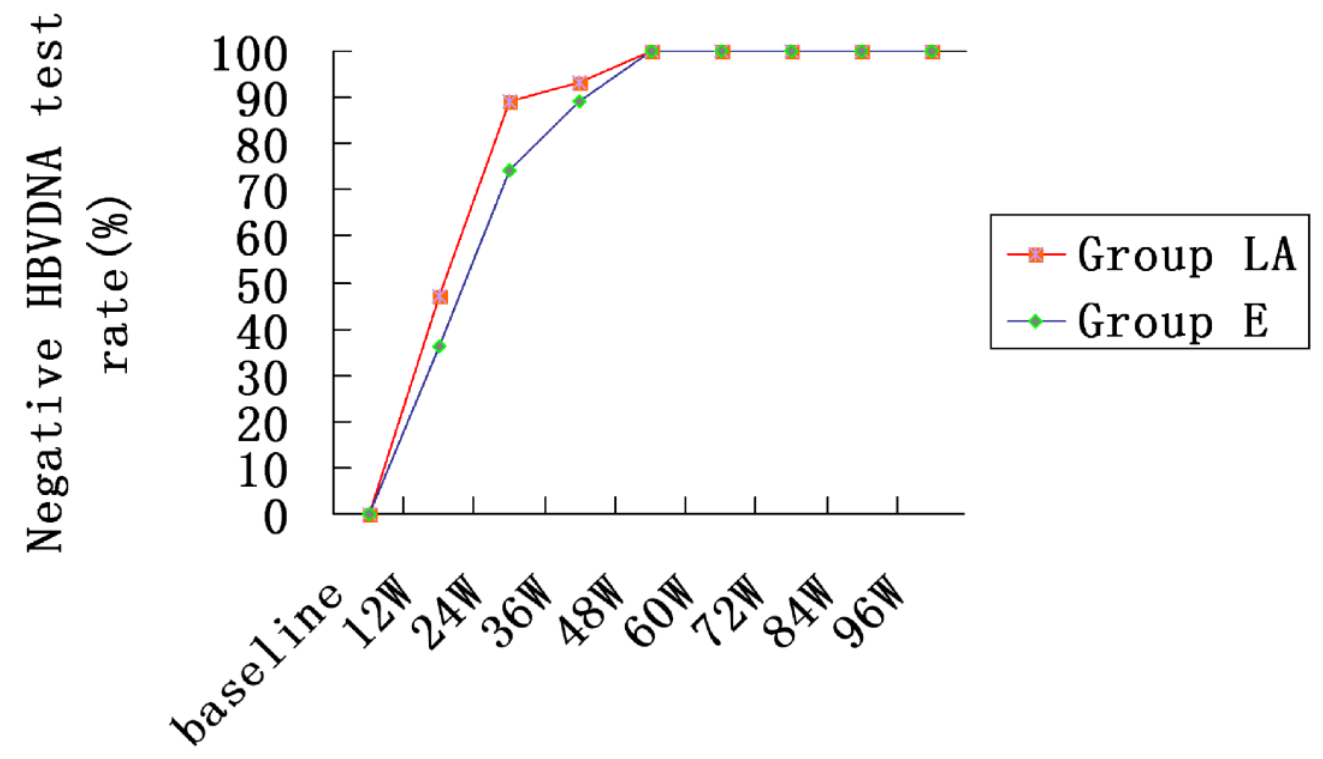

Treatment Duration

Figure 2. Percentage of negative HBV DNA tests.

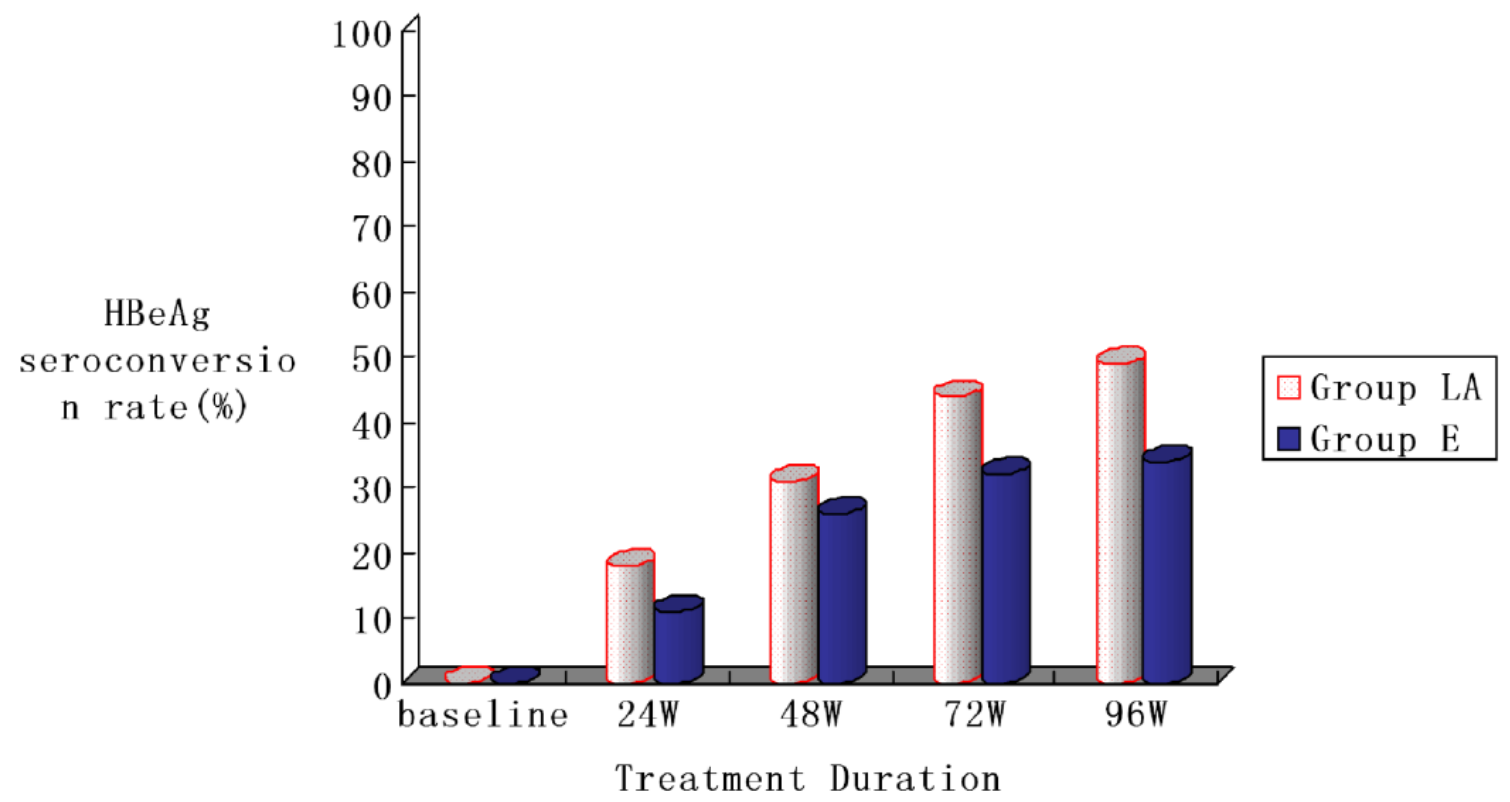

Figure 3. $\mathrm{HBeAg}$ seroconversion rate.

to improve. At 72 weeks, the $\mathrm{HBeAg}$ seroconversion rates of the LA and $E$ groups were $44 \%$ (20/45) and 32\% (15/47), respectively; the difference between two groups was not statistically significant $(X 2=1.53, P>0.05)$. At 96 weeks, HBeAg seroconversion of LA group (49\%) $(22 / 45)$ were higher than that of the E group (34\%) (16/47), but the difference was still no statistically significant $(X 2=2.09$, $P>0.05$ ) (Figure 3).

\section{Biochemical response (rates of ALT normalization)}

For the LA and E groups 12 weeks after trial initiation, serum ALT normalized in 56\% (25/45) and 53\% (25/47) of patients $(X 2=0.05, P>0.05)$, respectively. At 24 weeks, the percentages of patients with normalized serum ALT in the LA and $E$ groups were $96 \%(43 / 45)$ and $89 \%(42 / 47)$, respectively $\left(X^{2}=1.25, P>0.05\right)$. At 36 weeks, ALT 


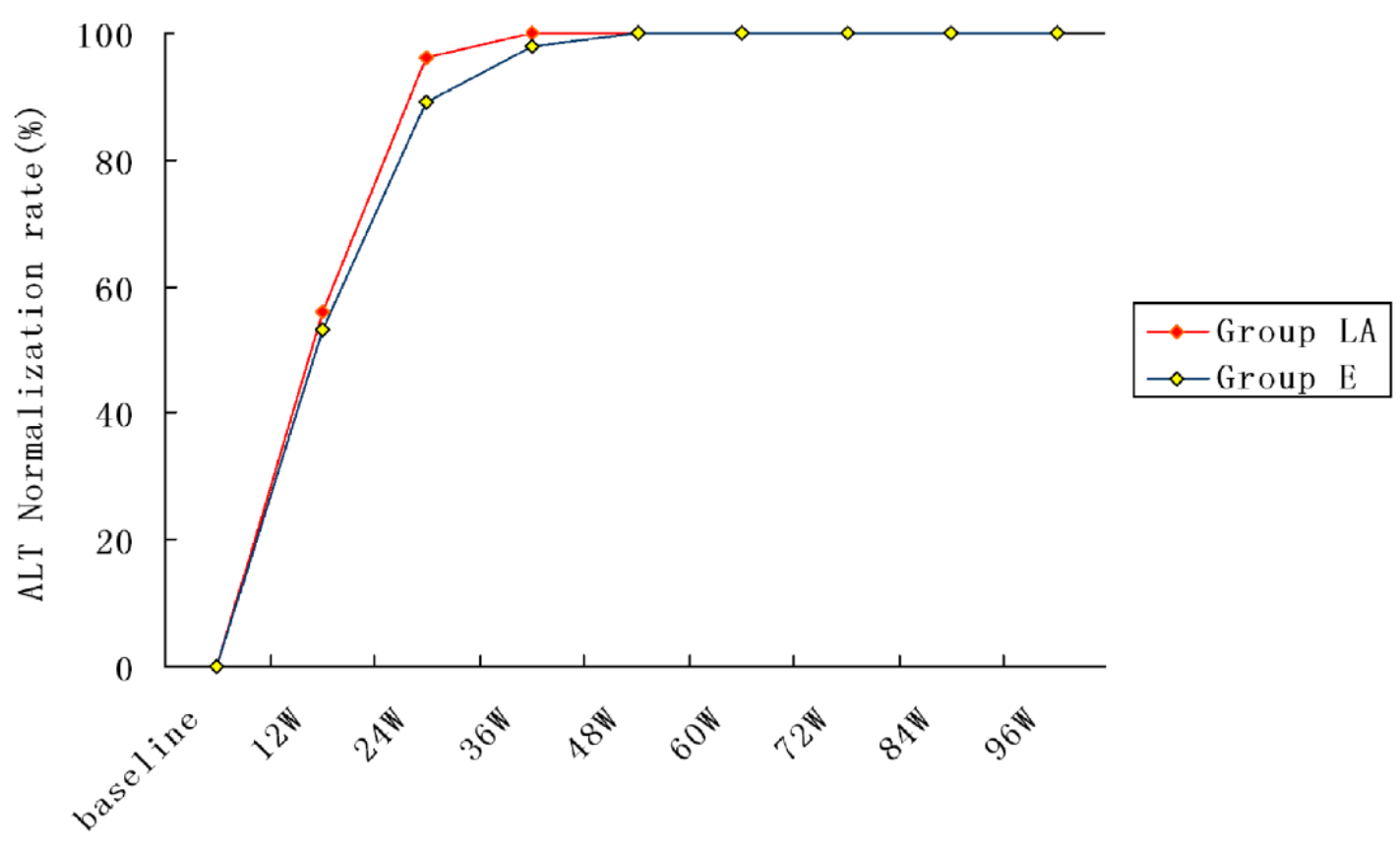

Treatment Duration

Figure 4. Percentage of patients with normalized serum ALT.

normalization rates in the LA and $E$ groups were $100 \%$ $(45 / 45)$ and $98 \%(46 / 47)(X 2=0.97, P>0.05)$. From 48 weeks, ALT normalization rates in two groups were $100 \%$ $(45 / 45)$ and $100 \%(47 / 47) \quad(P>0.05)$. None of these differences were statistically significant (Figure 4).

\section{Virological breakthrough and drug resistance}

During the 96-week treatment period, virological breakthrough did not occur in any of the 92 patients included in this study. That is, LAM-, ADV-, or ETVassociated mutations were not detected.

\section{Pharmacoeconomic analysis}

In the pharmacoeconomic analysis, we evaluated the direct costs related to treatment of the two groups. It is of note that, as previously mentioned, the costs related to antivirus of patients in two group were included in the final costs. The total costs include antiviral drug costs, outpatient service registration fee, adverse events processing fee, and assistant examination fee containing liver function, renal function, HBV-DNA, AFP, HBV-M and type-B ultrasonic (Figure 5).

In the pharmacoeconomic evaluation, the costs regarding antiviral drug costs were higher in the $\mathrm{E}$ group than in the LA group (RMB ¥25,824 vs. RMB $¥ 11,380$; $t=156.4, p<0.001)$. Costs were higher in the LA group only in the use of renal function. No statistical difference was found in costs regarding outpatient service registration fee, adverse events processing fee, and assistant examination fee $(p>0.05)$.

As seen in Figure 5, the analysis of the total costs per group, revealed greater economy in the LA group than in the $E$ group (RMB $¥ 14,480.13$ vs. RMB $¥ 28,818.47$; $t=164.78, p<0.001)$.

\section{Safety analysis}

Within the 96 weeks of clinical trial, we generally observed that the characteristics and rates of adverse reactions were comparable between the groups. About $18 \%$ of the patients developed at least one mild or moderate adverse reactions, which include: abnormal lab results (elevated ALT), fatigue, abdominal discomfort, upper abdominal pain, dizziness, insomnia, etc (Table 2). After receiving heteropathy, these symptoms soon get control.

\section{DISCUSSION}

Tremendous progress was made in the treatment of chronic hepatitis B in the past 10 years with the introduction of several novel nucleoside and nucleotide analogues. In clinical use, nucleoside/nucleotide analogues are uncomplicated, efficacious, and safe. Due to high replication rates of HBV, lack of proof reading or editing activity for reverse transcriptase, HBV mutations 


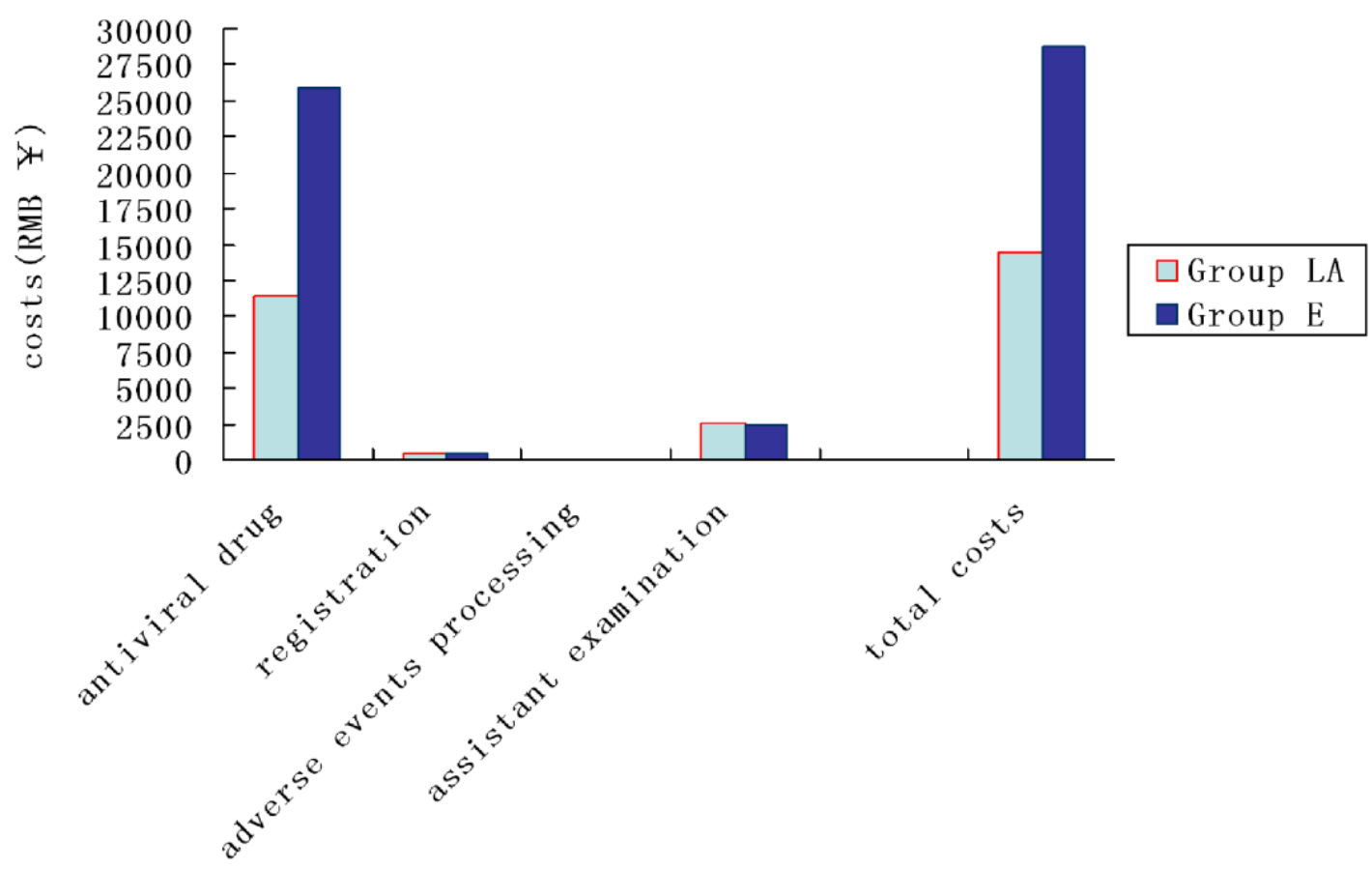

Figure 5. The cost analysis of the parameters investigated in both groups.

Table 2. Adverse events of patients by group.

\begin{tabular}{lcccccc}
\hline Group & Elevated ALT & Fatigue & Abdominal discomfort & Dizziness & Insomnia & Epigastric pain \\
\hline LA & 1 & 4 & 1 & 1 & 1 & 1 \\
E & 3 & 4 & 1 & 0 & 0 & 0 \\
\hline
\end{tabular}

can and do develop, resulting in drug resistance during long-term treatment. Drug resistance is one of the most important influencing factors limiting longterm nucleoside treatment for CHB patients (Papatheodoridis and Deutsch, 2008). Current strategy to management of HBV drug resistance includes rescue therapy, which may reduce the efficacy of follow-up pharmacotherapy, increase the risk of drug resistance, and lead to multidrug resistant HBV that may further limit treatment options (Moriconi et al., 2007). For long-term treatment, it is necessary to consider prevention or delay of drug resistance by developing efficacious therapy with low viral resistance. Drugs with high genetic barrier and/or low resistance such as entecavir are especially important in the prevention of drug resistance. Induction of sustained off-therapy virological and biochemical response at baseline with durable anti-HBe seroconversion in $\mathrm{HBeAg}$ positive patients is a satisfactory end point (European Association for the Study of the Live, 2012). However, entecavir is expensive, possibly tumorigenic, and no more efficacious than lamivudine in terms of $\mathrm{HBeAg}$ seroconversion (Liang, 2012), thereby limiting its widespread usage.

Another strategy to prevent or delay HBV drug resistance involves combination pharmacotherapy, where two or more antiviral drugs are co-administered starting at treatment initiation. Clinicians throughout the world have tested various approaches to multi-drug therapy. There is clinical evidence showing that lamivudine combined with adefovir dipivoxil can be used to reduce the rate of drug resistance in newly-diagnosed treatmentnaive, chronic hepatitis B patients or in patients with lamivudine-resistance (Seto et al., 2012; Sung et al., 2008).

Ideally, combination HBV therapy should offer compounded or complementary efficacy, low crossresistance, high resistance barrier, long-term safety, and economic feasibility. Even though lamivudine/adefovir combination therapy satisfies the former three requirements, it would nonetheless increase patients' economic burden and potentially induce multi-drug resistant HBV. Therefore, long-term usage of lamivudine/adefovir combination therapy may not be the preferred strategy for chronic hepatitis $B$. 
Tan et al. (2012) considers YMDD variants as naturallyoccurring mutations and lamivudine merely plays a selective role. Since adefovir belongs to a new generation of anti-HBV drugs, little is known about specific adefovir-resistant mutations. During the intensification phase, the combination group was coadministered lamivudine and adefovir, which managed both wild-type HBV as well as those with primary mutations, thereby preventing the selection of drug resistance HBV mutations in patients. The rate of development of HBV drug resistance is positively correlated with baseline viral load (Fung et al., 2009). Lamivudine has strong antiviral effects, where $30 \%$ of patients test negative for HBV DNA at three months, with peak of HBV DNA suppression at around 6 months. During the consolidation phase at 3 to 6 months, serum HBV DNA rapidly declines, thereby decreasing the likelihood of drug resistance.

Clinical studies indicate that the onset of HBV viral load suppression by adefovir is slower, requiring 2 to 3 months to reach the anticipated clinical response (Mao et al., 2007). However, in patients receiving lamivudine therapy for chronic hepatitis B, the YMDD mutation can be detected as early as 6 months (Liu et al., 2004). Given these time frames, a negative serum HBV DNA 3 to 6 months after initiation of combination lamivudine/adefovir therapy signals the an appropriate time to discontinue lamivudine therapy in order to reduce the rates of drug resistance and cross-resistance as well as the cost of long-term combination therapy as opposed to monotherapy with adefovir. This specific strategy and administration schedule of lamivudine/adefovir combination therapy takes advantage of the strengths of both individual drugs in order to maximize clinical efficacy and reduce drug resistance. With the YMDD mutation yet to appear and the ability of the rapidly declining HBV DNA levels at 12 weeks in predicting the long-term efficacy of adefovir (Hass et al., 2009), the possibility of future adefovir-resistance is significantly reduced while adefovir efficacy is potentially increased.

In general, pharmacoeconomic analysis consists of two essential elements: costs and outcome, which are, respectively the nominator and the denominator of the equation. The pharmacoeconomic analysis in this study was based on cost minimization, in which we compared the costs of two treatment modalities whose final outcome measure was the resolution of the Complete response rate composed of Rates of undetectable serum HBV DNA (virological response,VR), rates of $\mathrm{HBeAg}$ seroconversion and rates of ALT normalization(biochemical response, BR). The analysis showed that the costs of all items related to diminishing type antiviral combination of lamivudine and adefovir were lower than those related to the entecavir monotherapy (RMB ¥14,480.13 vs. RMB ¥28,818.47; $\mathrm{t}=164.78, P<0.001)$.

Our results indicated that, during the first 12 weeks of diminishing type antiviral combination of lamivudine and adefovir (LA), the HBV DNA suppression and ALT normalization rates were both comparable to the entecavir monotherapy $(E)$ group. Both therapy strategies effectively inhibit viral replication and improve liver function. The difference was not statistically significant. At weeks 24 and 48 of treatment, the difference in VR and HBeAg seroconversion between LA group and E group was not significant, while similar results were observed for the BR. However, after 48 weeks, $\mathrm{HBeAg}$ seroconversion of LA group continued to improve. At 96 weeks, $\mathrm{HBeAg}$ seroconversion of LA group were higher than that of the $E$ group, but the difference was still no statistically significant, while BR and VR in LA and E group were similar. At the same time, no virological breakthrough or drug resistance occurred in either of the two treatment groups by week 96 of the study. Both treatment strategies were well tolerated, with a low incidence of adverse reaction. One caveat of this study is that no matching placebos were employed in this study.

In summary, this study demonstrates that diminishing type antiviral combination of lamivudine and adefovir is economical, safe, and effective in HBeAg-positive chronic hepatitis $\mathrm{B}$. We propose that combination therapy with lamivudine and adefovir for 12 to 24 week followed by long-term adefovir monotherapy be recommended for widespread usage in $\mathrm{HBeAg}$-positive chronic hepatitis $\mathrm{B}$. This strategy was worthy for further clinical application in countries, where ETV is not available or very expensive. A larger study is needed to determine the long-term advantages and disadvantages between the 2 groups.

\section{ACKNOWLEDGEMENT}

We are indebted to the authors and patients of the primary studies included in this trial. There is no conflict of interest with any pharmaceutical organization regarding the material discussed in the manuscript.

\section{REFERENCES}

Ayoub WS, Keeffe EB (2008). Review article: current antiviral therapy of chronic hepatitis B. Aliment Pharmacol. Ther. 28:167-177.

Degertekin B, Lok AS (2009). Update on viral hepatitis: 2008. Curr. Opin. Gastroenterol. 25:180-185.

European Association for the Study of the Live (2012). EASL Clinical Practice Guidelines: Management of chronic hepatitis B virus infection. J. Hepatol. 57:167-185.

Fung JYY, Lai CL, Seto WK, Wang DKH, Yuen JCH, Yuen RMF (2009). Combination of baseline HBV DNA and ALT level with on-treatment HBV DNA response to select $\mathrm{HBeAg}$-positive patients for lamivudine therapy. APASAL.

Hass HG, Bock T, Nehls O, Kaiser S (2009). Rapid HBV DNA decrease (week 12) is an important prognostic factor for first-line treatment with adefovir dipivoxil for chronic hepatitis B. J. Gastroenterol. 44:871877.

Liang J, Tang YF, Wu FS, Deng X (2012). Entecavir versus lamivudine for the treatment of chronic hepatitis $B$ : a systematic review. Pharmazie 67:883-890.

Liu CJ, Huang WL, Chen PL, Lai MY, Kao JH, Chen DS (2004). End-of- 
treatment virologic response does not predict relapse after lamivudine treatment for chronic hepatitis B. World J. Gastroenterol. 10:3574-3578.

Mao YM, Ceng MD, Wei L, Xie Q, Lu ZM, Niu JQ, Chen YG, Lei BJ, Zhang HF, Yang JM, Li J, Tang Q, Wu GX, Cao AP (2007). A 48week, randomized, double-blind, parallel placebo-controlled, multicenter clinical trial of domestically-produced adefovir dipivoxil for the treatment of HBeAG-positive chronic hepatitis B. Liver 12:355-359.

Moriconi F, Colombatto P, Coco B, Ciccorossi P, Oliveri F, Flichman D, Maina AM, Sacco R, Bonino F, Brunetto MR (2007). Emergence of hepatitis B virus quasispecies with lower susceptibility to nucleos(t)ide analogues during lamivudine treatment. J. Antimicrob. Chemother. 60:341-349.

Papatheodoridis GV, Deutsch M (2008). Resistance issues in treating chronic hepatitis B. Future Microbiol. 3:525-538.

Seto WK, Liu K, Fung J, Wong DK, Yuen JC, Hung IF, Lai CL, Yuen MF (2012). Outcome of lamivudine-resistant chronic hepatitis B after up to 5 years of combination therapy with adefovir. Antivir. Ther. 17:1255-1262.

Sung JJ, Lai JY, Zeuzem S, Chow WC, Heathcote EJ, Perrillo RP, Brosgart CL, Woessner MA, Scott SA, Gray DF, Gardner SD (2008). Lamivudine compared with lamivudine and adefovir dipivoxil for the treatment of HBeAg-positive chronic hepatitis B. J. Hepatol. 48:728735.
Tan Y, Ding K, Su J, Trinh X, Peng Z, Gong Y, Chen L, Cui Q, Lei N, Chen X, Yu R (2012). The naturally occurring YMDD mutation among patients chronically infected HBV and untreated with lamivudine: a systematic review and meta-analysis. PLoS One 7:e32789.

Tenney DJ, Rose RE, Baldick CJ, Pokornowski KA, Eggers BJ, Fang J, Wichroski MJ, Xu D, Yang J, Wilber RB, Colonno RJ (2009). Longterm monitoring shows hepatitis B virus resistance to entecavir in nucleosidenaive patients is rare through 5 years of therapy. Hepatology 49:1503-1514.

Wang H, Ji YY, Yao GB, Ma XY, Xie Q, Pang HY, Wu SM, Li J, Chen CW, Xu XW, Gu EL (2013). Two years efficiency of lamivudine and adefovir dipivoxil combined therapy in chronic hepatitis B patients. Eur. Rev. Med. Pharmacol. Sci. 17:636-643. 